\title{
Advances in modeling transport phenomena in material-extrusion additive manufacturing: Coupling momentum, heat, and mass transfer
}

\begin{abstract}
Material-extrusion (MatEx) additive manufacturing involves layer-by-layer assembly of extruded material onto a printer bed and has found applications in rapid prototyping. Both material and machining limitations lead to poor mechanical properties of printed parts. Such problems may be addressed via an improved understanding of the complex transport processes and multiphysics associated with the MatEx process. Thereby, this review paper describes the current (last 5 years) state of the art modeling approaches based on momentum, heat and mass transfer that are employed in an effort to achieve this understanding. We describe how specific details regarding polymer chain orientation, viscoelastic behavior and crystallization are often neglected and demonstrate that there is a key need to couple the transport phenomena. Such a combined modeling approach can expand MatEx applicability to broader application space, thus we present prospective avenues to provide more comprehensive modeling and therefore new insights into enhancing MatEx performance.
\end{abstract}

Keywords: Material extrusion; Flow deposition; Heat transfer; Constitutive models; Flowinduced crystallization.

\section{Introduction}

Additive manufacturing (AM) is a processing technique that employs computer aided design (CAD) file to fabricate three dimensional objects using metals, ceramics, polymers, and composite materials [1-4]. However, filament-based material extrusion (MatEx) of thermoplastic polymers is one of the most common and economical AM techniques due to the easy operability, low material and energy requirements [5-7]. MatEx is also a relatively uncomplicated forming method that can be used to manufacture three dimensional parts with intricate geometric features [8]. MatEx is being widely used in different industries mainly because it can be used to print functional prototypes like brackets, wire harnesses, ducts, fixtures, and jigs rather than just labscale prototypes by carefully selecting the material and processing conditions [9]. Although MatEx has progressed significantly, its complexity demands further research to gain an in-depth understanding of the process and consequently ensure the repeatable production of consistent parts [10].

The typical MatEx based AM process has been schematically illustrated in Figure 1 (reprinted with permission from Ref. [11]). In this method, a thermoplastic polymer feed (either in the form of solid pellets or filament) is used to print parts of desired shapes. Briefly, the polymer is melted and extruded through a heated liquefier block (heated section in Fig. 1) via a pinch-roller mechanism (that maintains the feed flow rate). The polymer melt experiences shear rates $\sim 100 \mathrm{~s}^{-1}$ inside the nozzle that can have appreciable effect on the polymer chain orientation and stretch (denoted by Region 1 in Fig. 1) [7, 11]. After deposition on the build plate the extrudate cools down and the polymer chains relax (denoted by Region 2 in Fig. 1). 
Subsequently, the solid filament pushes more material through the nozzle which gets laid on the initially deposited layer where the material undergoes solidification and weld together to fabricate the final product. The print head then moves in the $\mathrm{x}$-y direction and print bed in the $\mathrm{z}$ direction to continue the print in a layer by layer manner till the entire part has been built. The interactions among the process controls, material properties, process parameters, and printed part properties (mechanical properties, surface roughness, surface finish, etc.) have been reviewed in great detail in previous reported literature [12-14].

In summary, flow of viscoelastic material through a nozzle, typically at elevated shear rates, coupled with rapid cooling and solidification (and crystallization in the case of some thermoplastics), affects part geometry, porosity, and mechanical strength [12, 13]. Ultimately, the part micro-structure determines the buildup of residual stresses and inter-layer (weld) strength. Thus, MatEx involves the simultaneous and co-dependent transfer of momentum, heat, and mass, which are intimately linked to end-part properties. An overview of these transport phenomena typical to polymer processing in general is provided by Bird [15]. A systematic way to analyze MatEx is via multi-scale multi-physics models that can simulate the entire print, accounting for four fundamental processes:

(a) flow behavior of the polymer melt $[15,16]$,

(b) heat transfer [17],

(c) viscoelastic properties (which affect anisotropy and inter-diffusion) [18], and

(d) solidification and crystallization $[19,20]$.

These processes occur across various length scales; from the size of a polymer molecule $(\mathrm{nm})$ to the scale of the part itself ( $\mathrm{mm}$ to $\mathrm{m}$ ).

The modelling approaches to be reviewed here provide powerful tools to explore these complex phenomena occurring across disparate length scales and aim to predict material-specific optimal printing parameters, as well as the mechanical performance of the final printed part. Although there is a substantial amount of current literature that investigate the effect of process variables on the print part properties through various experimental measurements [21-26] such approaches typically focus on empirical data fits rather than a fundamental understanding and model analysis of the key physics. Therefore, the ultimate goal of such models is to provide tools for quality control during MatEx that respond to the physical phenomena to help guide machine and material design (e.g. changes to heat capacity and thermal conductivity) for improved printing. However, deriving equations that link processing parameters directly to part properties is non-trivial.

In general, transport phenomena are described by three governing equations [15]: conservation of mass, conservation of momentum and the heat equation. That is for an evolving velocity field $u(\boldsymbol{x}, t)$, stress field $\sigma(\boldsymbol{x}, t)$, and temperature field $T(\boldsymbol{x}, t)$, which vary in both time $t$ and space $\boldsymbol{x}$, the governing equations are given by 


$$
\begin{gathered}
\frac{\partial \rho}{\partial t}+(\nabla \bullet \rho u)=0 \quad \text { Equation } 1 \\
\rho \frac{D u}{D t}=-\nabla p-[\nabla \bullet \sigma]+\rho g \text { Equation } 2 \\
\rho C_{P} \frac{\partial T}{\partial t}=\alpha \nabla^{2} T+\dot{q}_{V} \text { Equation } 3
\end{gathered}
$$

where, $\rho$ is the density, $\frac{D u}{D t}$ is the material derivative of the flow velocity, $\mathrm{p}$ is the pressure, $C_{P}$ is the specific heat capacity, $\alpha$ is the thermal diffusivity of the material, and $\dot{q_{V}}$ is the volumetric heat source term. Analytic solutions to these equations prove challenging even for simple fluids. For more complex materials, such as the polymer melts used in MatEx, the velocity, stress and temperature fields must also be coupled to an appropriate constitutive equation [27]. Whilst simple relations can be employed to capture shear-dependent viscosity, these do not capture complex (viscoelastic) phenomenon arising from the microstructure of the material. Also, semi-crystalline polymers require further consideration, since the crystallization kinetics [28] affect both the rheology and temperature (via, shear heating and latent heat). Moreover, flow can have interesting implications on the crystallization process [29] and hence the ultimate properties of the printed product. Figure 2 provides an overview of the multi-physics associated with the MatEx and further illustrates how improper control of one or more of these processes can lead to failure of the MatEx printing process.

A full computational model of the MatEx process would require evolving Eqs.1-3 forward in time across the spatial domain (which is also time-dependent due to the layer-by layer process), together with full non-linear coupling to a constitutive equation that is molecularlyaware and accounts for the multi-phase nature of semi-crystalline polymers. Despite the increase in computational power, this is an unwieldy task. Instead, a fundamental understanding of MatEx may be gained by simplifying the problem in various ways. (For example, considering steady-state behavior, reducing the spatial dimension, and decoupling the processes.) In this paper, we review recent advances (over the last 5 years) in modeling these complex transport phenomena for applications in MatEx AM. Table 1 highlights the current state of the art in modeling approaches for MatEx with reference to the fundamental processes modeled as well as the scale at which the simulations were performed.

We discuss models that consider material flow to predict the shape of the deposited layers in Section 2. Heat-transfer models that predict the thermal profiles over multiple length scales (from inside the nozzle to the final part) are discussed in Section 3. In Section 4, we review how these models can be coupled with classical polymer constitutive analyses to provide valuable insights into the micro-structural evolution and ultimate strength of a printed part after 
solidification. Classical polymer crystallization models can also be incorporated where appropriate to reveal details of the crystal content and morphology, which depend on both thermal and flow history. Finally, we address the challenges associated with these approaches, potential methodologies to address these challenges, and recommendations on developing comprehensive models to accurately represent the intricate transport phenomena occurring during the MatEx process.

\section{Momentum transport: Flow and Geometry}

In traditional polymer processing techniques (e.g. injection molding, extrusion etc.) where both shear and elongation flow of the polymer melt are of critical importance [15, 16], geometry of the extrudate is not usually significant since well-defined molds typically dictate the final geometry of the manufactured parts. In contrast, polymer flow through the nozzle and subsequent deposition determines the geometry of extruded roads in MatEx, and thus the fully assembled shape of the part itself $[30,31]$. The road geometry depends on both the print resolution and print speed [32] and is ultimately a result of the polymer's viscoelastic properties. Agassant et al. [33] highlight the relationship between print head velocity and pressure at the nozzle outlet. This relationship leads to an optimal operation window (Fig. 3a, reprinted with permission from Ref. [33]) that eliminates the risk of buckling (as illustrated in Figure 2), ensures continuous road deposition, and provides sufficient pressure to encourage inter-layer diffusion and subsequent adhesion. The shape of the roads also provides information regarding porosity [34], inter-road bonding [35], and thermal history [36]. The effect of the print parameters on the road geometry [32, 33] and surface roughness [37] of a printed part has also been investigated. The print speed, extrusion flow rate, and, gap between the nozzle head and print bed were found to have a pronounced effect on the shape of the deposited roads as well as the mechanism of extrude spreading on the print bed (hydrodynamically controlled vs. surface tension controlled) $[32,33]$. On the other hand, layer thickness was found to have a significant effect in determining the surface roughness of a printed part [37]. Bakrani Balani et al. [38] studied the effect of the printing parameters, rheological and thermal characteristics on the geometry of deposited roads of polylactic acid (PLA) during MatEx. The authors further developed a two-phase flow model that was employed to model the geometry of the deposited roads [38]. The simulation results (suggesting deformation of the extrudate during deposition on the printer bed) were in close agreement with the experimental findings using an optical microscope, demonstrating the robustness of the modeling approach [38].

Simple analytic models based on conservation of mass have been developed to predict the height, width and cross-sectional area of a single deposited road [30, 31]. While this approach gives a reasonable agreement with CT-scanning images, it is unable to provide a full description of the ovality of the road, which impacts the weld contact area between adjacent roads (in both the $\mathrm{x}$ and $\mathrm{z}$ directions), or the part shape. Thus, a number of full computational fluid dynamics (CFD) models have recently been presented [31, 39] and validated against optical microscopy experiments [32], as well as SEM images [40], as shown in Figures 3(b) and 3(c) 
(reprinted with permission from Refs. [32] and [40]), respectively. These analyses illustrate a range of road shapes, from circular to elongated rectangle, depending of print parameters (Fig. $3 b$, reprinted with permission from Ref. [32]). A new computationally-efficient volume conserving (VOLCO) model has also been developed [34] to capture the geometry at road-road interfaces and the porosity within a full 3D lattice. The flow model described was able to represent the printing of a full-size 3D lattice, rather than just a single filament and successfully described the experimental observations (Fig. 3d, reprinted with permission from Ref. [34]).

Other important geometrical aspects that have recently been considered via numeral modeling include surface instabilities along the road [38], and sagging of freely-supported roads [41]. While this progress has significantly enhanced our ability to simulate geometry, temperature-dependent viscoelasticity and crystallization must be coupled to these models to fully understand the complex flow dynamics. While power-law models have provided some insight to the spreading dynamics [33], a constitutive model that incorporates normal stress differences is necessary to capture extrudate swell effects [42]. Moreover, density changes during cooling, which are exaggerated during crystallization, are responsible for part shrinkage and warping (as highlighted in Figure 2 as well).

\section{Heat transfer}

Melt-based processing of polymers is associated with complex interactions between fluid mechanics and heat transfer in a non-Newtonian fluid system [17, 43]. Similarly, in the MatEx process the filament must be molten to flow through the nozzle and hence heat transfer significantly impacts the print speed [44]. The thermal profile of the polymer from nozzle through to deposition (Fig. 4a, reprinted with permission from Ref. [45]) also controls inter-road adhesion (also known as welding) through polymer diffusion, significantly impacting final part properties [40, 46-49]. Thus, the ability to accurately predict heat transfer is crucial to fully understanding MatEx.

Transient one-dimensional heat-transfer models considering conduction and natural convection, which can be solved via finite-difference methods, have been implemented to calculate inter-road bond strength of acrylonitrile butadiene styrene (ABS) with reasonable accuracy [50]. A similar approach, with the addition of radiation, has also been developed for big-area AM (BAAM), and is able to predict the temperature profiles and thermal gradients in thin walls which was validated by infrared imaging of carbon fiber (CF) reinforced ABS prints [51]. A 2-D approach with order-of-magnitude analysis was adopted by Osswald et al. [52] for a shear-thinning quasi-Newtonian fluid, which was validated using a custom piston-driven capillary setup. However, these models are insufficient to properly represent the temperature gradient within the deposited roads $[51,52]$. Accurate prediction of this thermal gradient is key to determining the cooling rate after deposition, and hence the evolution of weld strength in the printed parts [40].

With the improvement in computational capabilities, 3-D heat-transfer models for MatEx, which can be solved using finite-element (FE) methods, have been investigated [36, 53]. For 
example, a simulated thermal profile within the nozzle head is shown in Figure 4(b) (reprinted with permission from Ref. [54]) [54]. FE models have also been developed to capture rapid cooling during the deposition process [55], however assumptions regarding interlayer bonding resulted in predicted trends which overestimate the heat transfer measured using infrared imaging techniques. The entire MatEx process (die extrusion, road deposition, and subsequent cooling and consolidation) has also been modeled recently; the thermal profile of an extruded road from such an analysis is illustrated in Figure 4(c) (reprinted with permission from Ref. [40]) [40]. Zhang et al. [56] developed a space resolved, time dependent 3-D model to capture the thermal behavior during and after MatEx. The integrity of the welds formed between the layers was found to strongly dependent on the printing speed while residual stresses inside a print could be controlled by manipulating the cooling rate [56]. Zhou et al. [57] also developed a 3-D FE thermal model to describe temperature and stress distribution in a printed part of PLA. The simulation studies revealed that lower print temperature, reduced print speed, and lower layer thickness can mitigate the residual thermal stress and part distortion. Further examples of 3-D FE heat-transfer models can be found in Refs. [58, 59].

Arguably more important is the validation of analytical and numerical models via comparison to experimental measurements. Luo et al. [60] recently developed a heat transfer model based on previous modeling efforts on polymer melt flow in tubes [61] and 3D printer nozzles [62]. The thermal model provides an upper limit of the polymer feed rates that can be successfully printed using MatEx without jamming [60]. The authors validated their simulation results by performing experiments on a modified extruder setup and found that their model was in good agreement with model predictions, especially at a nozzle wall temperature range of $210^{\circ} \mathrm{C}-260^{\circ} \mathrm{C}$ [60]. A non-isothermal welding model was developed by Coasey et al. [63] and experimentally verified by interlaminar fracture toughness measurements. The model describes the effect of processing parameters and rheological properties on the degree of healing of the printed parts [63]. The melting behavior of PLA inside a MatEx nozzle was computationally modeled and validated using experiments [64]. The authors coupled a generalized Newtonian fluid model with the Phan-Thein-Tanner viscoelastic model to model the melting behavior and subsequent melt flow in the nozzle under high shear rates [64]. Edwards and Mackay [65] also developed a post-extrusion heating model for both amorphous and semi-crystalline polymers to minimize the formation of "shark-skin" defects during MatEx. Key works that account for radiative heat transfer effects have shown excellent agreement between the temperature profile in the nozzle prior to and after deposition [66], in the standoff region (between nozzle \& bed) [67], and on the print bed [45].

Despite this progress, it is apparent that the rheological properties of the melt significantly affect the heat transfer by influencing the flow characteristics (e.g. viscous heating) [55]. Hence, to completely understand the complexities of the heat-transfer process, appropriate polymer constitutive models must be considered. Mackey et al. analyzed the problem in the nozzle (where melting and extrusion occurs) using a generalized Newtonian fluid framework to model the rheological behavior [68], reporting that heat-transfer affects the pressure drop across 
the nozzle and limits print speed. On the scale of a final printed part, Brenken et al. coupled a 3$\mathrm{D}$ heat-conduction model with temperature-dependent viscoelasticity to simulate the transient thermal profile in a functional part as highlighted in Figure 4(d) (reprinted with permission from Ref. [69]) [69]. Moreover, polymer crystallization and material shrinkage are also incorporated into their model-crucial ingredients for predicting latent heat effects and part geometry.

\section{Anisotropy and inter-diffusion}

Viscoelasticity plays a crucial role in polymer processing [70] and hence it is of considerable importance in MatEx as well $[68,71]$. It has been shown that typical shear rates are sufficient to orient and stretch the polymer molecules [72]. Thus, as well as affecting heat transfer in the nozzle via shear heating [73], and influencing the geometry of a deposited road via extrudate swell [42], polymer deformation (anisotropy) may persist at solidification. For an amorphous polymer, Fig. 5a illustrates the typical degree of residual alignment across a single road locked in due to the glass transition, as predicted by the numerical model of McIlroy et al. [72].

Moreover, the key to ensuring part strength is successful welding of the polymer chains at road-road interfaces via inter-diffusion [74]. The poor interlayer bonding between the printed layers is highlighted in Figure 2. As a rule of thumb, if there is sufficient time above the glasstransition temperature, $\mathrm{T}_{\mathrm{g}}$, for the polymer to diffuse its radius of gyration, then bulk strength should be recovered in the weld region [75]. Fig. 5b (reprinted with permission from Ref. [55]) demonstrates a typical cooling profile found in MatEx; for these print conditions (and thermal properties) there is approximately one second above $\mathrm{T}_{\mathrm{g}}$ available for inter-diffusion [55]. Polymer alignment leads to anisotropic diffusion (in the direction of chain orientation) [76] and may hinder this welding process, although this effect is found to be small for polycarbonate (PC) [72] and for PLA as shown in Fig. 5c [72].

The role of polymer entanglements is also crucial to ensuring strength at road-road interfaces [74]. It is proposed that MatEx can lead to flow-induced disentanglement of the polymer network [77] and that only partial re-entanglement of the network is achieved during cooling [72]. McIlroy et al. [72] suggest that it is this partial entanglement, rather than anisotropic diffusion, that is responsible for weld weakness in amorphous parts. However, this is yet to be validated experimentally. Nevertheless, residual viscoelastic stresses affect part properties, in particular reducing the tensile properties of printed parts (Fig. 5d, reprinted with permission from Ref. [78]).

Since power-law models are not sufficient to capture this molecular-scale behaviour, recent works by McIlroy et al. have employed a molecularly-aware constitutive model [11, 72, $79,80]$, which requires knowledge of both the reptation and Rouse times of the polymer (obtained from linear rheology). In particular, McIlroy and Olmsted [80] prescribes the geometry of the deposited road, which enables the flow field to be solved directly from conservation of mass independently of the constitutive (Rolie-Poly) equation using finite-difference methods. The authors find that the melt experiences significant strain rates within the nozzle, which are able to substantially stretch and orient the polymers. Furthermore, the deposition process 
involving the $90^{\circ}$ turn dominates the deformation and significantly disentangles the melt. Although this approach [80] provides a computationally efficient method to investigate a range of printing conditions, the interplay between viscoelasticity and the weld geometry is neglected. Since the Rolie-Poly model provides a simple one-mode constitutive equation for the stress tensor, it can be readily integrated into full CFD calculations to capture this behavior. Recent advances by Xia et al. [39] incorporate a reduced Rolie-Poly model into a full finite-element computation of the flow field to investigate the effect of these viscoelastic stresses on the deposition geometry.

\section{Polymer crystallization}

The fundamental mechanisms of polymer crystallization are detailed in a review article elsewhere [81]. The use of semi-crystalline polymers in MatEx has sparked significant interest but is largely relegated to academic studies [82-86]. Briefly, the crystalline regions in these polymers act as physical crosslinks that restrict movement of the polymer chains, thereby strengthening the material $[19,20]$. Thus, crystallinity is a major factor to determining tensile properties, and ultimately dictates the application of printed parts. For example, Figure 6(a) (data adapted from Ref. [87]) highlights the variation in tensile strength of a common engineering thermoplastic, polyphenylene sulfide (PPS), with the percent crystallinity of the printed parts. The tensile strength increases by $\sim 37 \%$ with increasing crystalline content due to variations in printing conditions.

The most common approach to modeling polymer crystallization considers the formation of nuclei and subsequent growth into a stable crystalline framework. However, traditional isothermal models fail to capture the complex effects of the steep temperature gradients and cooling rates found in MatEx. As noted in the heat transfer section, Brenken et al. [69] track the thermal profile and crystallization process during MatEx using a dual (Velisaris) non-isothermal model which has been summarized in Figure 4(d) (reprinted with permission from Ref. [69]). Further to this work, a finite-difference model has been developed to account for multiple crystallization mechanisms, shear stress evolution, and more complicated thermal histories [88]. The model predicts both the thermal distribution and evolution of the crystal fraction throughout a printed part, and these processes which are then applied to novel models for predicting the degree of healing and residual stress at each layer. This is the first healing model that accounts for crystallinity and the experimentally determined bond strength was found to be close to the theoretical predictions.

In the models discussed thus far, the polymers are assumed to crystallize quiescently, i.e. the effect of flow is neglected. However, it is well known that even slight alignment of the polymers at the onset of nucleation can strongly enhance the nucleation rate [89], and consequently lead to accelerated crystallization times. McIlroy et al. [11, 79] have recently extended their finite-difference modelling approach (incorporating the Schneider rate equations) to show that there exists a MatEx-operation window in which crystallization times are reduced due to shear in the nozzle (Fig. 6b, reprinted with permission from Ref. [11]). Furthermore, it is shown that this flow-enhanced crystallization is localized to a thin boundary layer near to the 
road surface, leading to the development of smaller crystal structures in the weld region (Fig. 6c, reprinted with permission from Ref. [79]). These results are in agreement with in-situ Raman spectroscopy and optical microscopy measurements.

Shmueli et al. [90] coupled in-situ wide angle X-ray scattering with infrared imaging during MatEx of PLA filaments to study the morphology development. The authors found that thermal profile as well the printing direction (with respect to the X-ray beam) significantly affected the structure of the deposited roads [90]. Subsequent work performed by the same group [91] using polypropylene (PP) by connecting a MatEx printer with a X-ray scattering beamline. The authors observed the formation of shish-kebab crystal structure post printing, which nucleated at the surface of the filaments and gradually advanced toward the center of the filament [91]. The experimental method provided both time and space dependent data for the crystallization process and can be a valuable resource for capturing the detailed kinetics as well as the microstructure development during a print. Welding at the interface of two successive printed layers was found to occur due to polymer chain relaxation and diffusion [91]. In a more recent study, Nogales et al. [92] monitored the microstructure development and weld formation during MatEx of PP by performing in-situ X-ray scattering experiments in the synchrotron beamline. The crystallization mechanism during printing of the layers was found to be similar to that encountered during quiescent crystallization of PP. Moreover, the printed layer had increased crystalline content in the bulk with respect to the interfacial regions indicating a gradient in crystallinity across a single layer [92]. The authors suggested that this can improve interlayer welding and hence improve the mechanical properties of MatEx printed parts since interlayer welding is directly related with the extent of polymer chain diffusion between the layers [92]. Whilst inter-diffusion must precede the crystallization to ensure sufficient inter-road adhesion, the development of smaller crystal structures may be considered beneficial to improving weld properties [37]. Moreover, McIlroy et al. [37,38] propose a simple comparison of time scales, which can be applied to any printing material, so that print conditions can be optimized to ensure (or eliminate) flow-enhanced crystallization.

\section{Discussion and future directions}

Numerous limitations exist in 3D printing technology, as discussed in Ref. [93]; multiscale molecular modeling approaches are critical in addressing challenges in material diversity and print speed. A useful tool to evaluate the 'printability' of a range of materials, including high-temperature thermoplastics, fiber-reinforced thermoplastics, and low-viscosity thermosets has been presented by Duty et al. [94], and a range of approaches have been tested for improving part properties:

- Since molecular weight can significantly affect the welding dynamics [33], tuning the molecular-weight distribution may be used as an avenue for optimization. In particular, Levenhagen et al. [95] show that a bi-modal distribution can improve mechanical properties and isotropy of printed parts; the addition of a small-molecular weight tail enhances the interdiffusion at the welds. Current printing models consider only a single mode description of the 
molecular-weight distribution, however new capabilities are emerging [96], offering exciting opportunities for a more detailed modeling approach.

- The addition of particulate additives can also improve part properties. In particular, Brenken et al. [97] and Fallon et al. [98] review a range of different composite systems, comprising of discontinuous and continuous fiber-reinforced polymers. The materials are characterized by the fiber alignment, which is oriented parallel to the direction of the deposited road, thus can lead mechanical limitations in the transverse direction. Some progress has been made in modeling the material flow and orientation in these systems [99], but many open question remain including wetting properties, bond formation, and thermomechanical solidification behavior.

- There is also precedent for the employment of post-printing annealing to remove residual viscoelastic stresses and increase the final crystal fraction, thereby improving thermal [100] and mechanical properties (Fig. 6d, data adapted from Ref. [101]) [102]. However, it has been shown that annealing may not result in the desired uniformity of spherulite sizes [79]. In particular, the model of Mcllroy et al. [79] shows that a higher nucleation density may be 'templated' into the road by the flow during printing. Thus, on annealing, smaller flow-enhanced spherulites are revealed in the weld regions, as seen by optical microscopy (Fig. 6c, reprinted with permission from Ref. [79]). Nevertheless, it is proposed that these smaller spherulites can give rise to more ductile fracture.

Although great progress has been in made understanding MatEx using the modelling approaches discussed, many challenges remain; foremost being that coupling viscoelastic flow, heat transfer, and crystallization kinetics is computationally demanding [39, 40]. Table 1 provides a list of recent literature on modeling the MatEx process. As evident from the data, there are very few works that take into account all four of the fundamental processes that occur simultaneously during the printing process. Future research must address this concern even though it requires substantial computation power. Another important observation from Table 1 is the amount of research on modeling the extrudate exiting the printer nozzle or on the deposition of roads on the printer bed which comfortably outnumber the research works that deal with simulating actual functional parts. It is expected that this trend will start to change in the near future with more industries and academic groups investigating large area AM [103-106] and bridge the gap between the current simulation scale $(\sim \mu \mathrm{m}-\mathrm{mm})$ and part dimensions $(\sim \mathrm{m})$.

Quantitative predictions also rely on thorough materials characterization, including linear viscoelasticity, nucleation and crystal growth rates, as well as thermal properties, which remains non-trivial since the thermoplastic polymer properties for elevated temperature processing in MatEx are usually highly temperature dependent [107]. The Additive Manufacturing Benchmark (AM-Bench), focused primarily on MatEx and selective laser sintering, has been created as a platform for performing extensive in-situ and ex-situ to generate a huge repository of experimental data. The goal of the AM-Bench is to gain valuable insights into the current modeling endeavors by comparing the simulation results against the rigorously controlled benchmark data [108]. One of the current limitations of the simulation capabilities is the failure 
to describe spatial evolution of microstructure in a printed part but strides have been made in modeling the same for smaller build volumes. It is expected that incorporating the multiphysics described in this paper with the mechanics (e.g. residual strain/stress) of the printed part and optimizing the computational demands will lead to the development of models that can be of great industrial relevance [108].

Moreover, the profound effects of flow on polymer crystallization is still not fully understood [89] - in fact, even assumptions must be made on the nature of quiescent nucleation and continuum-level models that are able to incorporate the full complexity of the crystallization process remain in their infancy. Finally, there is experimental evidence of a phenomenon known as co-crystallization [109-111], which results in improved mechanical properties of a part, but models that account for this mechanism during MatEx are yet to be developed.

\section{References}

1. Herzog D, Seyda V, Wycisk E, Emmelmann C (2016) Additive manufacturing of metals. Acta Materialia 117:371-392. https://doi.org/10.1016/j.actamat.2016.07.019

2. Deckers J, Vleugels J, Kruth J-P (2014) Additive manufacturing of ceramics: A review. Journal of Ceramic Science and Technology 5:245-260. https://doi.org/10.4416/JCST2014-00032

3. Jasiuk I, Abueidda DW, Kozuch C, et al (2018) An Overview on Additive Manufacturing of Polymers. JOM 70:275-283. https://doi.org/10.1007/s11837-017-2730-y

4. Ning F, Cong W, Qiu J, et al (2015) Additive manufacturing of carbon fiber reinforced thermoplastic composites using fused deposition modeling. Composites Part B: Engineering 80:369-378. https://doi.org/10.1016/j.compositesb.2015.06.013

5. Ambrosi A, Pumera M (2016) 3D-printing technologies for electrochemical applications. Chemical Society Reviews 45:2740-2755

6. Gomez-Gras G, Jerez-Mesa R, Travieso-Rodriguez JA, Lluma-Fuentes J (2018) Fatigue performance of fused filament fabrication PLA specimens. Materials \& Design 140:278-285

7. Northcutt LA, Orski SV, Migler KB, Kotula AP (2018) Effect of processing conditions on crystallization kinetics during materials extrusion additive manufacturing. Polymer 154:182-187

8. Sun Q, Rizvi GM, Bellehumeur CT, Gu P (2008) Effect of processing conditions on the bonding quality of FDM polymer filaments. Rapid Prototyping Journal 14:72-80

9. Huang Y, Leu MC, Mazumder J, Donmez A (2015) Additive manufacturing: current state, future potential, gaps and needs, and recommendations. Journal of Manufacturing Science and Engineering 137:014001

10. Gao W, Zhang Y, Ramanujan D, et al (2015) The status, challenges, and future of additive manufacturing in engineering. Computer-Aided Design 69:65-89.

https://doi.org/10.1016/j.cad.2015.04.001 
11. Mcllroy C, Graham RS (2018) Modelling flow-enhanced crystallisation during fused filament fabrication of semi-crystalline polymer melts. Additive Manufacturing 24:323-340

12. Turner BN, Strong R, Gold SA (2014) A review of melt extrusion additive manufacturing processes: I. Process design and modeling. Rapid Prototyping Journal 20:192-204. https://doi.org/10.1108/RPJ-01-2013-0012

13. Gold SA, Turner BN (2015) A review of melt extrusion additive manufacturing processes: II. Materials, dimensional accuracy, and surface roughness. Rapid Prototyping Journal 21:250-261. https://doi.org/10.1108/RPJ-02-2013-0017

14. Parandoush $P$, Lin D (2017) A review on additive manufacturing of polymer-fiber composites. Composite Structures 182:36-53. https://doi.org/10.1016/j.compstruct.2017.08.088

15. Bird RB (2002) Transport phenomena. Appl Mech Rev 55:R1-R4.

https://doi.org/10.1115/1.1424298

16. George KE (2009) Non-Newtonian fluid mechanics and polymer rheology. In: Thomas S, Weimin $Y$ (eds) Advances in Polymer Processing. Woodhead Publishing, pp 13-46

17. Bergman TL, Incropera FP, Lavine AS, DeWitt DP (2011) Introduction to Heat Transfer. John Wiley \& Sons

18. Ferry JD (1980) Viscoelastic Properties of Polymers. John Wiley \& Sons

19. Reiter G, Sommer J-U (2003) Polymer Crystallization: Obervations, Concepts and Interpretations. Springer Science \& Business Media

20. Reiter G, Strobl GR (2007) Progress in Understanding of Polymer Crystallization. Springer

21. Lubombo C, Huneault MA (2018) Effect of infill patterns on the mechanical performance of lightweight 3D-printed cellular PLA parts. Materials Today Communications 17:214-228. https://doi.org/10.1016/j.mtcomm.2018.09.017

22. Mahmood S, Qureshi AJ, Goh KL, Talamona D (2017) Tensile strength of partially filled FFF printed parts: experimental results. Rapid Prototyping Journal 23:122-128. https://doi.org/10.1108/RPJ08-2015-0115

23. García Plaza E, Núñez López PJ, Caminero Torija MÁ, Chacón Muñoz JM (2019) Analysis of PLA Geometric Properties Processed by FFF Additive Manufacturing: Effects of Process Parameters and Plate-Extruder Precision Motion. Polymers 11:1581. https://doi.org/10.3390/polym11101581

24. Young DJ, Otten C, Czabaj MW (2019) Effect of Processing Parameters on Interlayer Fracture Toughness of Fused Filament Fabrication Thermoplastic Materials. In: Kramer S, Jordan JL, Jin H, et al (eds) Mechanics of Additive and Advanced Manufacturing, Volume 8. Springer International Publishing, Cham, pp 77-79 
25. Tsouknidas A, Pantazopoulos M, Katsoulis I, et al (2016) Impact absorption capacity of 3D-printed components fabricated by fused deposition modelling. Materials \& Design 102:41-44. https://doi.org/10.1016/j.matdes.2016.03.154

26. Zandi MD, Jerez-Mesa R, Lluma-Fuentes J, et al (2020) Experimental analysis of manufacturing parameters' effect on the flexural properties of wood-PLA composite parts built through FFF. Int J Adv Manuf Technol 106:3985-3998. https://doi.org/10.1007/s00170-019-04907-4

27. Larson RG (2013) Constitutive Equations for Polymer Melts and Solutions: Butterworths Series in Chemical Engineering. Butterworth-Heinemann

28. Piorkowska E, Rutledge GC (2013) Handbook of Polymer Crystallization. John Wiley \& Sons

29. Mcllroy C (2019) A fundamental rule: Determining the importance of flow prior to polymer crystallization. Physics of Fluids 31:113103. https://doi.org/10.1063/1.5129119

30. Hebda M, Mcllroy C, Whiteside B, et al (2019) A method for predicting geometric characteristics of polymer deposition during fused-filament-fabrication. Additive Manufacturing 27:99-108. https://doi.org/10.1016/j.addma.2019.02.013

31. Comminal R, Serdeczny MP, Pedersen DB, Spangenberg J (2018) Numerical modeling of the strand deposition flow in extrusion-based additive manufacturing. Additive Manufacturing 20:68-76. https://doi.org/10.1016/j.addma.2017.12.013

32. Serdeczny MP, Comminal R, Pedersen DB, Spangenberg J (2018) Experimental validation of a numerical model for the strand shape in material extrusion additive manufacturing. Additive Manufacturing 24:145-153. https://doi.org/10.1016/j.addma.2018.09.022

33. Agassant J-F, Pigeonneau F, Sardo L, Vincent M (2019) Flow analysis of the polymer spreading during extrusion additive manufacturing. Additive Manufacturing 100794. https://doi.org/10.1016/j.addma.2019.100794

34. Gleadall A, Ashcroft I, Segal J (2018) VOLCO: A predictive model for 3D printed microarchitecture. Additive Manufacturing 21:605-618. https://doi.org/10.1016/j.addma.2018.04.004

35. Rodriguez JF, Thomas JP, Renaud JE (2000) Characterization of the mesostructure of fused-deposition acrylonitrile-butadiene-styrene materials. Rapid Prototyping Journal 6:175-186. https://doi.org/10.1108/13552540010337056

36. Costa SF, Duarte FM, Covas JA (2017) Estimation of filament temperature and adhesion development in fused deposition techniques. Journal of Materials Processing Technology 245:167179

37. Anitha R, Arunachalam S, Radhakrishnan P (2001) Critical parameters influencing the quality of prototypes in fused deposition modelling. Journal of Materials Processing Technology 118:385388. https://doi.org/10.1016/S0924-0136(01)00980-3 
38. Bakrani Balani S, Chabert F, Nassiet V, Cantarel A (2019) Influence of printing parameters on the stability of deposited beads in fused filament fabrication of poly(lactic) acid. Additive Manufacturing 25:112-121. https://doi.org/10.1016/j.addma.2018.10.012

39. Xia H, Lu J, Tryggvason $\mathrm{G}$ (2019) A numerical study of the effect of viscoelastic stresses in fused filament fabrication. Computer Methods in Applied Mechanics and Engineering 346:242-259. https://doi.org/10.1016/j.cma.2018.11.031

40. Gilmer EL, Mansfield C, Gardner JM, et al (2019) Characterization and Analysis of Polyetherimide: Realizing Practical Challenges of Modeling the Extrusion-Based Additive Manufacturing Process. In: Polymer-Based Additive Manufacturing: Recent Developments. ACS Books

41. Xia H, Lu J, Tryggvason G (2019) Simulations of fused filament fabrication using a front tracking method. International Journal of Heat and Mass Transfer 138:1310-1319. https://doi.org/10.1016/j.ijheatmasstransfer.2019.04.132

42. Heller BP, Smith DE, Jack DA (2016) Effects of extrudate swell and nozzle geometry on fiber orientation in Fused Filament Fabrication nozzle flow. Additive Manufacturing 12:252-264

43. Denn MM (2008) Polymer Melt Processing: Foundations in Fluid Mechanics and Heat Transfer. Cambridge University Press

44. Mackay ME, Swain ZR, Banbury CR, et al (2017) The performance of the hot end in a plasticating 3D printer. Journal of Rheology 61:229-236. https://doi.org/10.1122/1.4973852

45. Ravoori D, Lowery C, Prajapati H, Jain A (2019) Experimental and theoretical investigation of heat transfer in platform bed during polymer extrusion based additive manufacturing. Polymer Testing 73:439-446. https://doi.org/10.1016/j.polymertesting.2018.11.025

46. Davis CS, Hillgartner KE, Han SH, Seppala JE (2017) Mechanical strength of welding zones produced by polymer extrusion additive manufacturing. Additive Manufacturing 16:162-166. https://doi.org/10.1016/j.addma.2017.06.006

47. Pourali M, Peterson AM (2019) Thermal Modeling of Material Extrusion Additive Manufacturing. In: Polymer-Based Additive Manufacturing: Recent Developments. American Chemical Society, pp 115-130

48. Seppala JE, Han SH, Hillgartner KE, et al (2017) Weld formation during material extrusion additive manufacturing. Soft Matter 13:6761-6769. https://doi.org/10.1039/C7SM00950J

49. Seppala JE, Migler KD (2016) Infrared thermography of welding zones produced by polymer extrusion additive manufacturing. Additive manufacturing 12:71-76

50. Coogan TJ, Kazmer DO (2017) Bond and part strength in fused deposition modeling. Rapid Prototyping Journal 23:414-422. https://doi.org/10.1108/RPJ-03-2016-0050

51. Compton BG, Post BK, Duty CE, et al (2017) Thermal analysis of additive manufacturing of largescale thermoplastic polymer composites. Additive Manufacturing 17:77-86.

https://doi.org/10.1016/j.addma.2017.07.006 
52. Osswald TA, Puentes J, Kattinger J (2018) Fused filament fabrication melting model. Additive Manufacturing 22:51-59. https://doi.org/10.1016/j.addma.2018.04.030

53. Costa SF, Duarte FM, Covas JA (2015) Thermal conditions affecting heat transfer in FDM/FFE: a contribution towards the numerical modelling of the process. Virtual and Physical Prototyping 10:35-46. https://doi.org/10.1080/17452759.2014.984042

54. Wang P, Zou B, Xiao H, et al (2019) Effects of printing parameters of fused deposition modeling on mechanical properties, surface quality, and microstructure of PEEK. Journal of Materials Processing Technology 271:62-74. https://doi.org/10.1016/j.jmatprotec.2019.03.016

55. D'Amico A, Peterson AM (2018) An adaptable FEA simulation of material extrusion additive manufacturing heat transfer in 3D. Additive Manufacturing 21:422-430.

https://doi.org/10.1016/j.addma.2018.02.021

56. Zhang J, Wang XZ, Yu WW, Deng YH (2017) Numerical investigation of the influence of process conditions on the temperature variation in fused deposition modeling. Materials \& Design 130:5968. https://doi.org/10.1016/j.matdes.2017.05.040

57. Zhou X, Hsieh S-J, Sun Y (2017) Experimental and numerical investigation of the thermal behaviour of polylactic acid during the fused deposition process. Virtual and Physical Prototyping 12:221233. https://doi.org/10.1080/17452759.2017.1317214

58. Zhou X, Hsieh S-J (2017) Thermal analysis of fused deposition modeling process using infrared thermography imaging and finite element modeling. In: Thermosense: Thermal Infrared Applications XXXIX. International Society for Optics and Photonics, p 1021409

59. Zhang Y, Shapiro V (2018) Linear-Time Thermal Simulation of As-Manufactured Fused Deposition Modeling Components. J Manuf Sci Eng 140:071002. https://doi.org/10.1115/1.4039556

60. Luo C, Wang X, Migler KB, Seppala JE (2020) Upper bound of feed rates in thermoplastic material extrusion additive manufacturing. Additive Manufacturing 32:101019.

https://doi.org/10.1016/j.addma.2019.101019

61. Agur EE, Vlachopoulos J (1981) Heat transfer to molten polymer flow in tubes. Journal of Applied Polymer Science 26:765-773. https://doi.org/10.1002/app.1981.070260302

62. AtifYardimci M, Hattori T, Guceri SI, Danforth SC (1997) Thermal analysis of fused deposition. In: 1997 International Solid Freeform Fabrication Symposium

63. Coasey K, Hart KR, Wetzel E, et al (2020) Nonisothermal Welding in Fused Filament Fabrication. Additive Manufacturing 101140. https://doi.org/10.1016/j.addma.2020.101140

64. Phan DD, Horner JS, Swain ZR, et al (2020) Computational fluid dynamics simulation of the melting process in the fused filament fabrication additive manufacturing technique. Additive Manufacturing 33:101161. https://doi.org/10.1016/j.addma.2020.101161

65. Edwards DA, Mackay M Post-Extrusion Heating in 3-D Printing. J Heat Transfer HT-19-1460: https://doi.org/10.1115/1.4046343 
66. Ravoori D, Prajapati H, Talluru V, et al (2019) Nozzle-integrated pre-deposition and post-deposition heating of previously deposited layers in polymer extrusion based additive manufacturing. Additive Manufacturing 28:719-726. https://doi.org/10.1016/j.addma.2019.06.006

67. Prajapati H, Ravoori D, Jain A (2018) Measurement and modeling of filament temperature distribution in the standoff gap between nozzle and bed in polymer-based additive manufacturing. Additive Manufacturing 24:224-231. https://doi.org/10.1016/j.addma.2018.09.030

68. Phan DD, Swain ZR, Mackay ME (2018) Rheological and heat transfer effects in fused filament fabrication. Journal of Rheology 62:1097-1107. https://doi.org/10.1122/1.5022982

69. Brenken B, Barocio E, Favaloro A, et al (2019) Development and validation of extrusion deposition additive manufacturing process simulations. Additive Manufacturing 25:218-226

70. Tadmor Z, Gogos CG (2013) Principles of Polymer Processing. John Wiley \& Sons

71. Mackay ME (2018) The importance of rheological behavior in the additive manufacturing technique material extrusion. Journal of Rheology 62:1549-1561. https://doi.org/10.1122/1.5037687

72. Mcllroy C, Olmsted PD (2017) Disentanglement effects on welding behaviour of polymer melts during the fused-filament-fabrication method for additive manufacturing. Polymer 123:376-391

73. Gutowski T, Jiang S, Cooper D, et al (2017) Note on the Rate and Energy Efficiency Limits for Additive Manufacturing. Journal of Industrial Ecology 21:S69-S79. https://doi.org/10.1111/jiec.12664

74. Ge T, Pierce F, Perahia D, et al (2013) Molecular Dynamics Simulations of Polymer Welding: Strength from Interfacial Entanglements. Phys Rev Lett 110:098301. https://doi.org/10.1103/PhysRevLett.110.098301

75. Agrawal G, Wool RP, Dozier WD, et al (1996) Interdiffusion of polymers across interfaces. Journal of Polymer Science Part B: Polymer Physics 34:2919-2940. https://doi.org/10.1002/(SICI)10990488(199612)34:17<2919::AID-POLB6>3.0.CO;2-L

76. Hunt TA, Todd BD (2009) Diffusion of linear polymer melts in shear and extensional flows. J Chem Phys 131:054904. https://doi.org/10.1063/1.3202868

77. Ianniruberto G, Marrucci G (2013) Convective constraint release (CCR) revisited. Journal of Rheology 58:89-102. https://doi.org/10.1122/1.4843957

78. Wu W, Geng P, Li G, et al (2015) Influence of layer thickness and raster angle on the mechanical properties of 3D-printed PEEK and a comparative mechanical study between PEEK and ABS. Materials 8:5834-5846

79. Mcllroy C, Seppala JE, Kotula AP (2019) Combining Modeling and Measurements To Predict Crystal Morphology in Material Extrusion. In: Polymer-Based Additive Manufacturing: Recent Developments. American Chemical Society, pp 85-113 
80. Mcllroy C, Olmsted PD (2017) Deformation of an amorphous polymer during the fused-filamentfabrication method for additive manufacturing. Journal of Rheology 61:379-397

81. Zhang MC, Guo B-H, Xu J (2017) A Review on Polymer Crystallization Theories. Crystals 7:4. https://doi.org/10.3390/cryst7010004

82. Das A, Marnot AEC, Fallon JJ, et al (2020) Material Extrusion-Based Additive Manufacturing with Blends of Polypropylene and Hydrocarbon Resins. ACS Appl Polym Mater 2:911-921. https://doi.org/10.1021/acsapm.9b01127

83. Schirmeister CG, Hees T, Licht EH, Mülhaupt R (2019) 3D printing of high density polyethylene by fused filament fabrication. Additive Manufacturing 28:152-159. https://doi.org/10.1016/j.addma.2019.05.003

84. Peng F, Jiang $\mathrm{H}$, Woods A, et al (2019) 3D Printing with Core-Shell Filaments Containing High or Low Density Polyethylene Shells. ACS Appl Polym Mater 1:275-285.

https://doi.org/10.1021/acsapm.8b00186

85. Spoerk M, Gonzalez-Gutierrez J, Lichal C, et al (2018) Optimisation of the Adhesion of Polypropylene-Based Materials during Extrusion-Based Additive Manufacturing. Polymers 10:490. https://doi.org/10.3390/polym10050490

86. Stoof D, Pickering K (2018) Sustainable composite fused deposition modelling filament using recycled pre-consumer polypropylene. Composites Part B: Engineering 135:110-118. https://doi.org/10.1016/j.compositesb.2017.10.005

87. Fitzharris ER, Watt I, Rosen DW, Shofner ML (2018) Interlayer bonding improvement of material extrusion parts with polyphenylene sulfide using the Taguchi method. Additive Manufacturing 24:287-297

88. Anderegg DA In-Situ Monitoring and Simulations of the Non-Isothermal Crystallization of FFF Printed Materials. Master of Science Thesis, Virginia Tech

89. Graham RS (2019) Understanding flow-induced crystallization in polymers: A perspective on the role of molecular simulations. Journal of Rheology 63:203-214.

https://doi.org/10.1122/1.5056170

90. Shmueli Y, Jiang J, Zhou Y, et al (2019) Simultaneous in Situ X-ray Scattering and Infrared Imaging of Polymer Extrusion in Additive Manufacturing. ACS Appl Polym Mater 1:1559-1567. https://doi.org/10.1021/acsapm.9b00328

91. Shmueli Y, Lin Y-C, Lee S, et al (2019) In Situ Time-Resolved X-ray Scattering Study of Isotactic Polypropylene in Additive Manufacturing. ACS Appl Mater Interfaces 11:37112-37120. https://doi.org/10.1021/acsami.9b12908

92. Nogales A, Gutiérrez-Fernández E, García-Gutiérrez M-C, et al (2019) Structure Development in Polymers during Fused Filament Fabrication (FFF): An in Situ Small- and Wide-Angle X-ray Scattering Study Using Synchrotron Radiation. Macromolecules. https://doi.org/10.1021/acs.macromol.9b01620 
93. Oropallo W, Piegl LA (2016) Ten challenges in 3D printing. Engineering with Computers 32:135148. https://doi.org/10.1007/s00366-015-0407-0

94. Duty C, Ajinjeru C, Kishore V, et al (2018) What makes a material printable? A viscoelastic model for extrusion-based 3D printing of polymers. Journal of Manufacturing Processes 35:526-537. https://doi.org/10.1016/j.jmapro.2018.08.008

95. Levenhagen NP, Dadmun MD (2018) Interlayer diffusion of surface segregating additives to improve the isotropy of fused deposition modeling products. Polymer 152:35-41. https://doi.org/10.1016/j.polymer.2018.01.031

96. Boudara VAH, Peterson JD, Leal LG, Read DJ (2018) Nonlinear rheology of polydisperse blends of entangled linear polymers: Rolie-Double-Poly models. Journal of Rheology 63:71-91. https://doi.org/10.1122/1.5052320

97. Brenken B, Barocio E, Favaloro A, et al (2018) Fused filament fabrication of fiber-reinforced polymers: A review. Additive Manufacturing 21:1-16. https://doi.org/10.1016/j.addma.2018.01.002

98. Fallon JJ, McKnight SH, Bortner MJ (2019) Highly Loaded Fiber Filled Polymers for Material Extrusion: A Review of Current Understanding. Additive Manufacturing 100810. https://doi.org/10.1016/j.addma.2019.100810

99. Stupp C (2019) Enhancing the processing and product design of additive manufactured fiber reinforced polymers by fused filament fabrication. PhD Thesis, Technische Universiteit Eindhoven

100. Prajapati $H$, Chalise $D$, Ravoori $D$, et al (2019) Improvement in build-direction thermal conductivity in extrusion-based polymer additive manufacturing through thermal annealing. Additive Manufacturing 26:242-249. https://doi.org/10.1016/j.addma.2019.01.004

101. Dong J, Mei C, Han J, et al (2019) 3D printed poly(lactic acid) composites with grafted cellulose nanofibers: Effect of nanofiber and post-fabrication annealing treatment on composite flexural properties. Additive Manufacturing 28:621-628. https://doi.org/10.1016/j.addma.2019.06.004

102. Hart KR, Dunn RM, Sietins JM, et al (2018) Increased fracture toughness of additively manufactured amorphous thermoplastics via thermal annealing. Polymer 144:192-204. https://doi.org/10.1016/j.polymer.2018.04.024

103. Duty CE, Kunc V, Compton B, et al (2017) Structure and mechanical behavior of Big Area Additive Manufacturing (BAAM) materials. Rapid Prototyping Journal 23:181-189

104. Kishore V, Ajinjeru C, Nycz A, et al (2017) Infrared preheating to improve interlayer strength of big area additive manufacturing (BAAM) components. Additive Manufacturing 14:7-12. https://doi.org/10.1016/j.addma.2016.11.008

105. Chesser P, Post B, Roschli A, et al (2019) Extrusion control for high quality printing on Big Area Additive Manufacturing (BAAM) systems. Additive Manufacturing 28:445-455.

https://doi.org/10.1016/j.addma.2019.05.020 
106. Russell T, Heller B, Jack DA, Smith DE (2018) Prediction of the Fiber Orientation State and the Resulting Structural and Thermal Properties of Fiber Reinforced Additive Manufactured Composites Fabricated Using the Big Area Additive Manufacturing Process. Journal of Composites Science 2:26. https://doi.org/10.3390/jcs2020026

107. Ravoori D, Alba L, Prajapati H, Jain A (2018) Investigation of process-structure-property relationships in polymer extrusion based additive manufacturing through in situ high speed imaging and thermal conductivity measurements. Additive Manufacturing 23:132-139. https://doi.org/10.1016/j.addma.2018.07.011

108. Levine L, Lane B, Heigel J, et al (2020) Outcomes and Conclusions from the 2018 AM-Bench Measurements, Challenge Problems, Modeling Submissions, and Conference. Integr Mater Manuf Innov 9:1-15. https://doi.org/10.1007/s40192-019-00164-1

109. Awaja F, Zhang S (2015) Self-bonding of PEEK for active medical implants applications. Journal of Adhesion Science and Technology 29:1593-1606

110. Bonten C, Schmachtenberg E (2001) A new hypothesis to describe the mechanisms acting in a welded joint of semicrystalline thermoplastics. Polymer Engineering \& Science 41:475-483

111. Xue Y-Q, Tervoort TA, Rastogi S, Lemstra J (2000) Welding behavior of semicrystalline polymers. 2. Effect of cocrystallization on autoadhesion. Macromolecules 33:7084-7087 


\section{List of Figures}

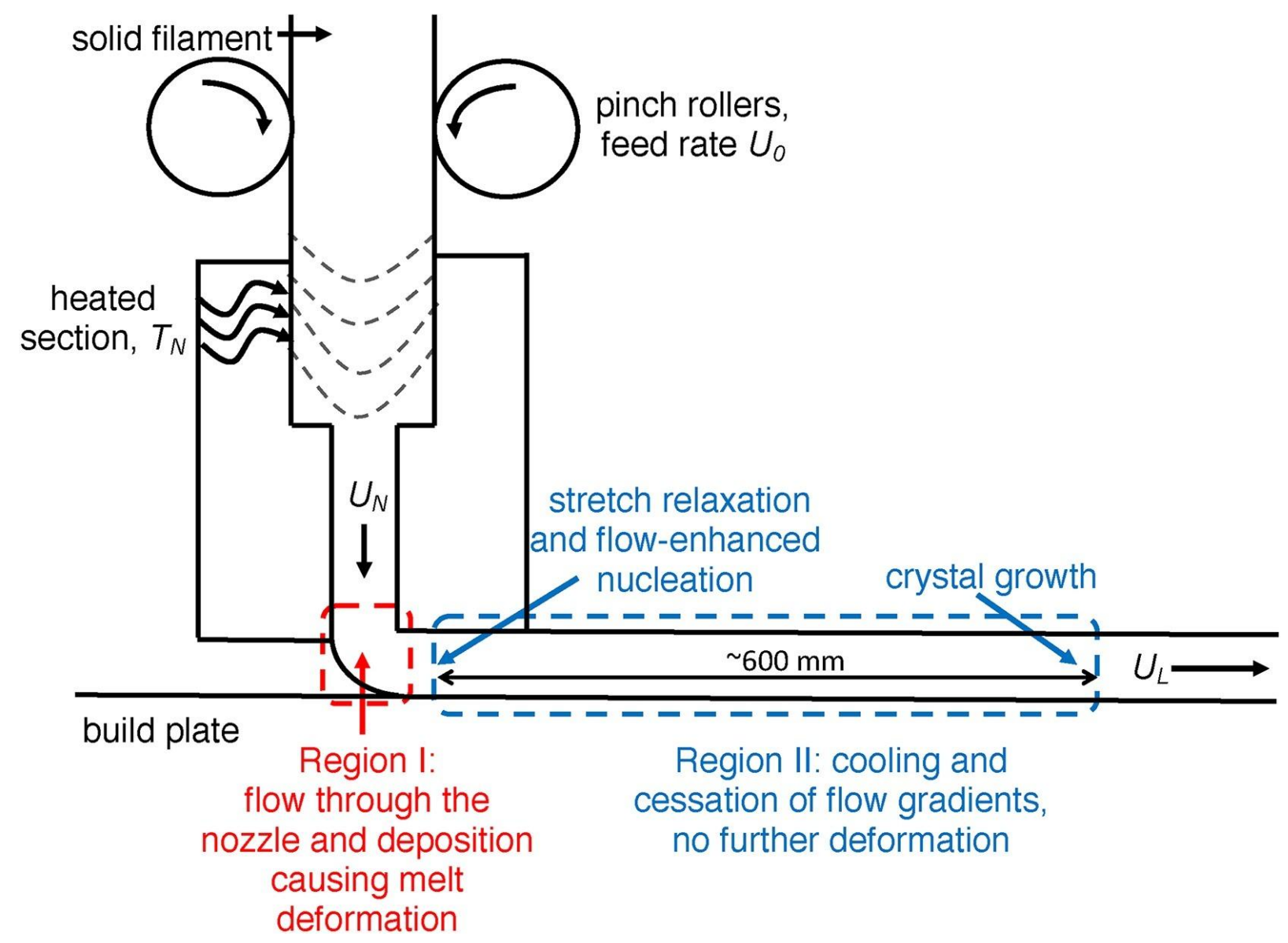

Fig. 1: Schematic of the MatEx based 3D printing process. The solid polymer filament is fed into the heated section (at a temperature of $T_{N}$ ) at a constant rate $\left(U_{0}\right)$ using the pinch roller mechanism. The polymer melt is deposited on the build plate (print bed) at a constant extrusion speed $\left(U_{N}\right)$ which is usually kept equal to the print bed speed $\left(U_{L}\right)$. The flow profile inside the nozzle is highlighted by the dotted lines. Region 1 highlights the melt flow region in the nozzle and subsequent deposition on the print bed while Region II represents the rapid cooling of the polymer extrudate and relaxation of the polymer chains. For a crystalline material, the crystallization process is initiated in Region II (image reprinted from Ref. [11] with permission from Elsevier). 


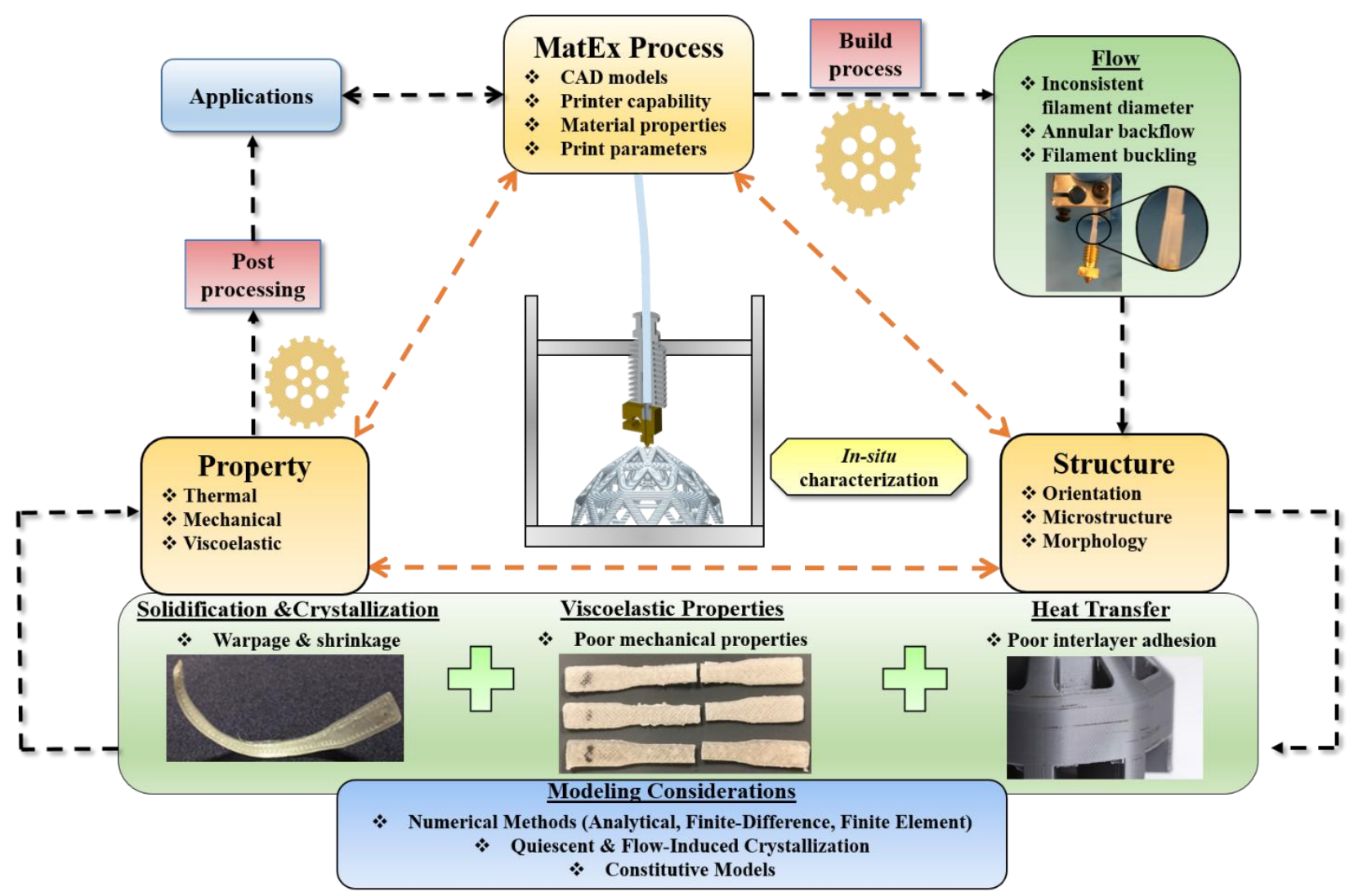

Fig. 2: Overview of the process-structure-property relationships in material extrusion (MatEx) based additive manufacturing (AM). Green boxes indicate the critical physical phenomena associated with the process and the modeling approaches toward these phenomena are reviewed in this paper. 

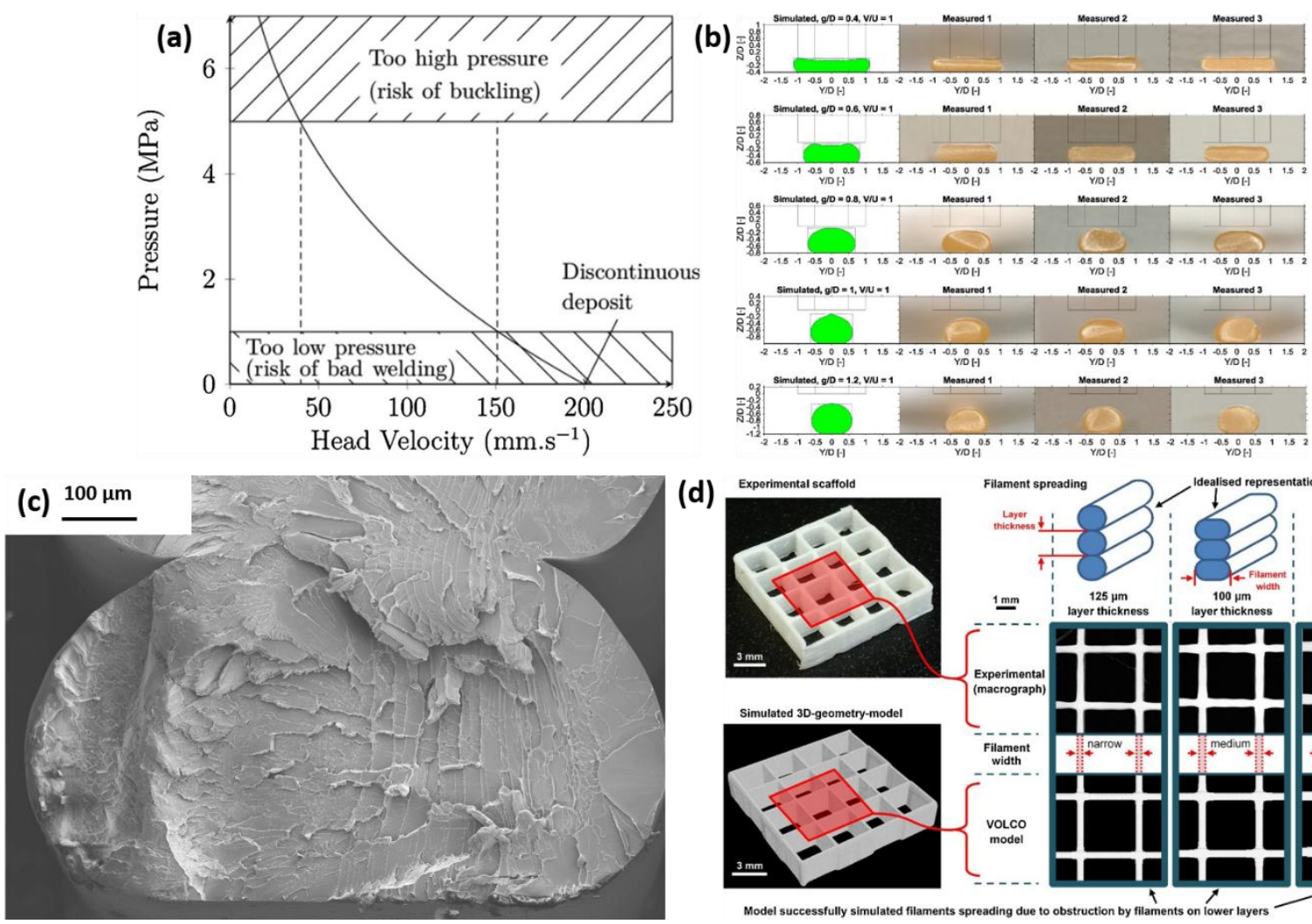

(d)

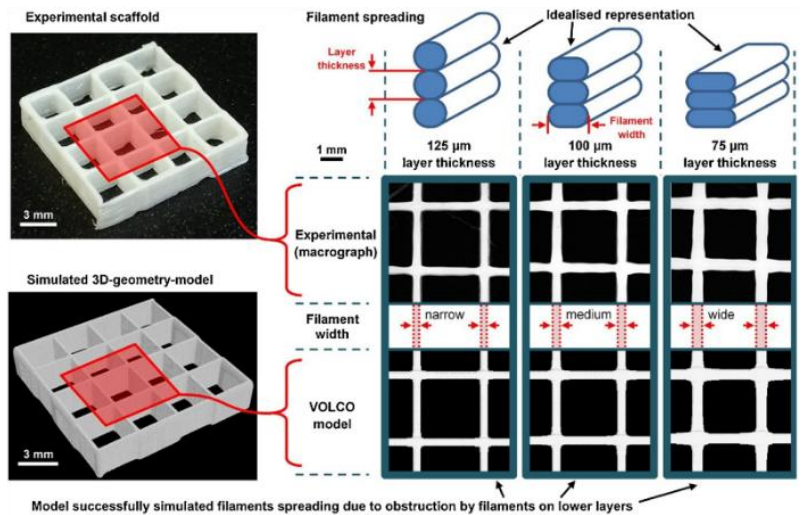

Fig. 3: (a) Phase map of the pressure across the printer nozzle as a function of print velocity showing the risks associated that can lead to print failure (image reprinted from Ref. [33] with permission from Elsevier); (b) Cross-sectional shapes of the extruded filaments from CFD simulations and as observed experimentally using optical microscopy using PLA (image reprinted Ref. [32] with permission from Elsevier); (c) SEM image of a cross-section of a single layer of print using polyether imide (PEI) (image reprinted with permission from Ref. [40] Copyright 2019 American Chemical Society); (d) Experimental 3D printed lattices and simulations of the lattice models as generated by the VOLCO model as a function of layer thickness. The filament spreading as a function of layer thickness was accurately captured by the VOLCO model (image reprinted from Ref. [34] under the terms of the Creative Commons CCBY license). 
(a)
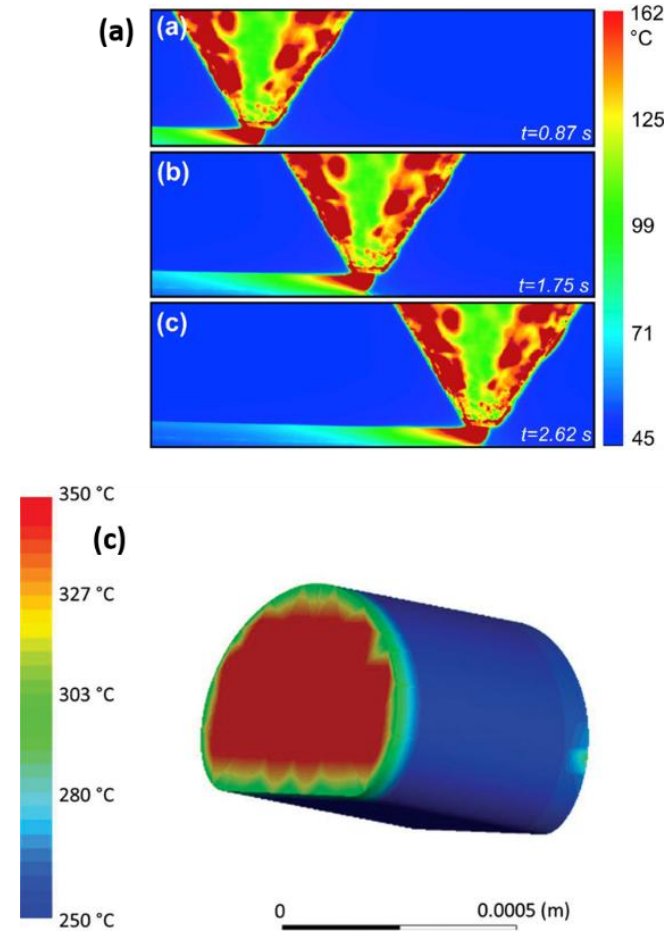

(c)

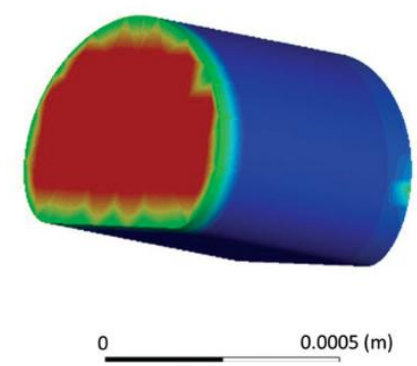

(b)

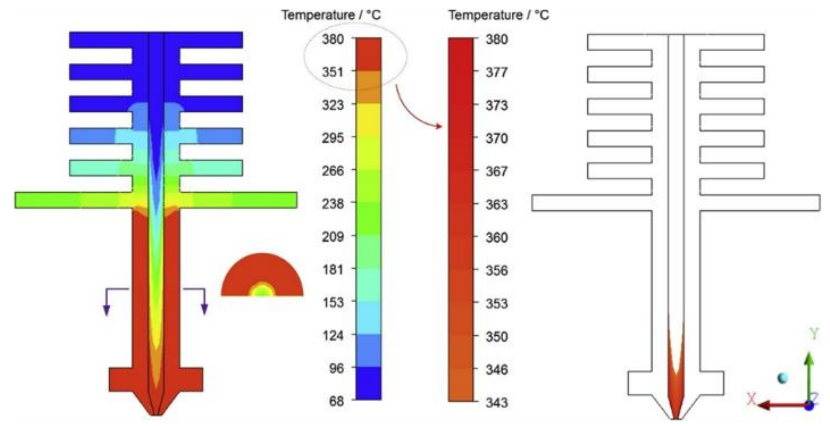

(d)

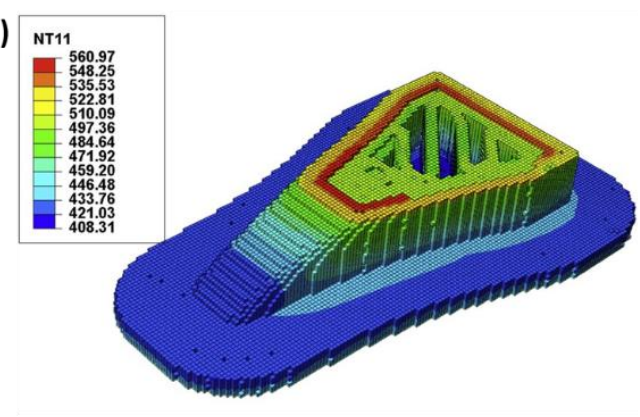

Fig. 4: (a) Infrared thermographs obtained at three different times for rastering of a single road of print where the nozzle moves from left to right (image reprinted from Ref. [45] with permission from Elsevier); (b) FE simulations of the thermal profile inside a typical MatEx nozzle (image reprinted from Ref. [54] with permission from Elsevier); (c) the thermal profile at a cross-section of the filament (image reprinted from Ref. [40] Copyright 2019 American Chemical Society); (d) simulated thermal profile of an entire printed part (image reprinted from Ref. [69] with permission from Elsevier). 

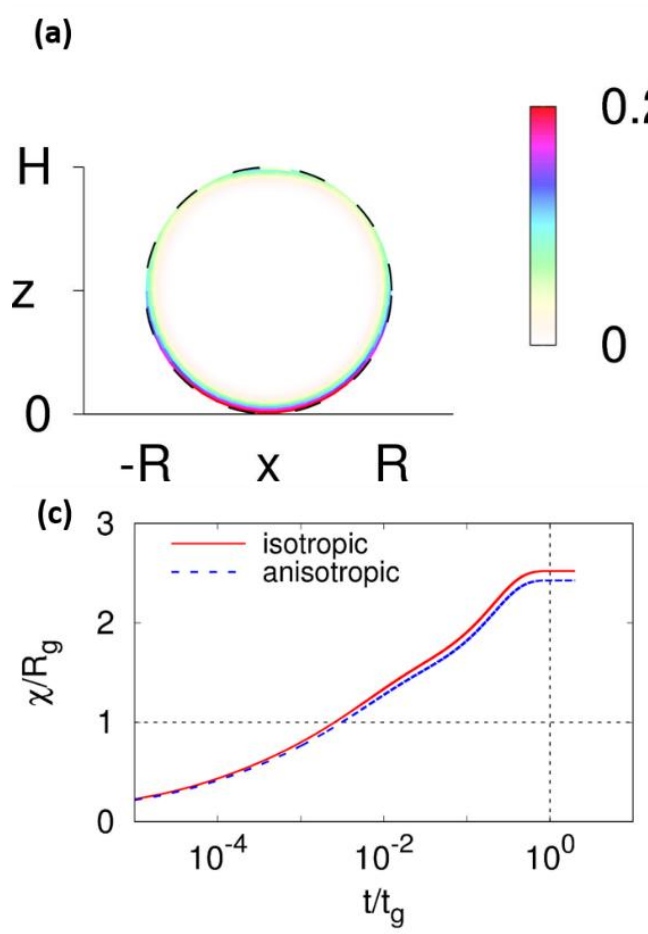

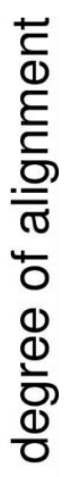

(b)

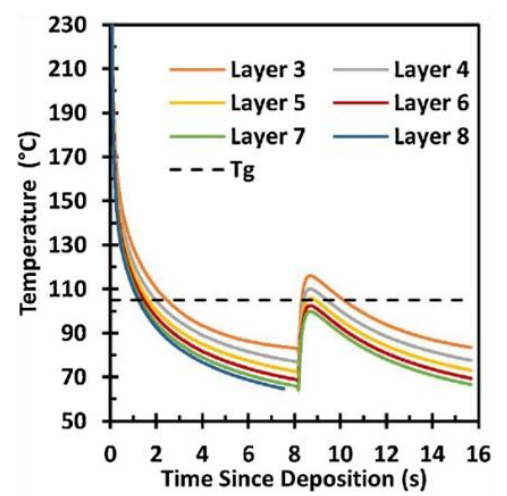

(d)

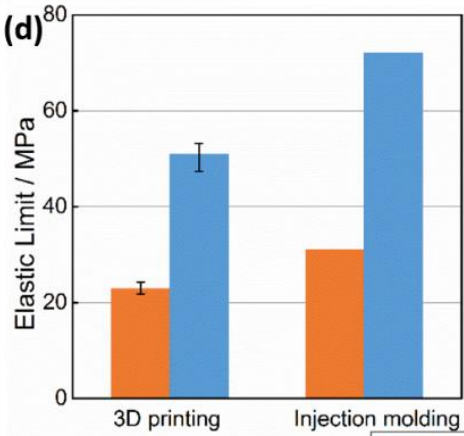

Fig. 5: (a) Residual alignment in a single deposited road of PLA printed at $120 \mathrm{~mm} / \mathrm{s}$ and $190^{\circ} \mathrm{C}$, as predicted by the numerical model described in Ref. [72]; (b) Prediction of the thermal profiles of the deposited layers using FE simulations; the different layers spend varying time periods above $T_{g}$ which determines the extent of their mobility (image reprinted from Ref. [55] with permission from Elsevier); (c) The polymer diffusion distance, $\chi$, scaled by the polymer size, $R_{g}$ (radius of gyration), as a function of time. Time scaled by the time taken to reach the glass transition temperature, so that at $\mathrm{t} / \mathrm{t}_{\mathrm{g}}=1, \mathrm{~T}=T_{g}$. The effects of polymer alignment in the flow give rise to anisotropic diffusion, which hinders diffusion between filaments, i.e., in the transverse z-direction. See Ref. [72] for details of the model; (d) Reduction in tensile properties of printed ABS and polyether-ether-ketone (PEEK) samples compared to injection molded parts (image reprinted from Ref. [78] under the Creative Commons Attribution License). 
(a)

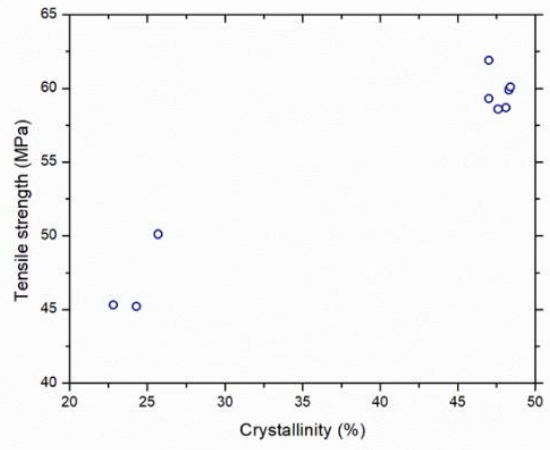

(c)

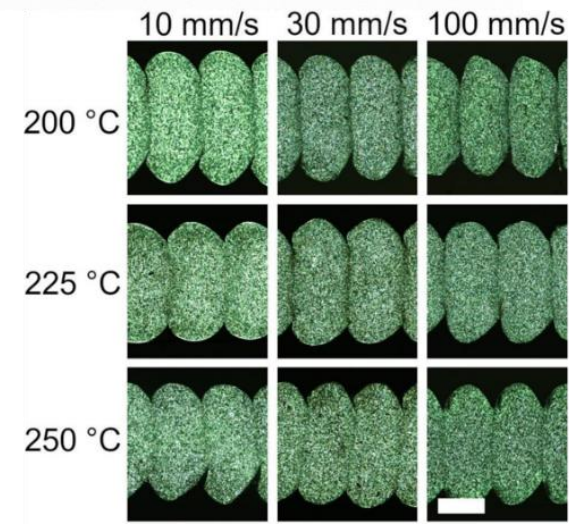

(b)

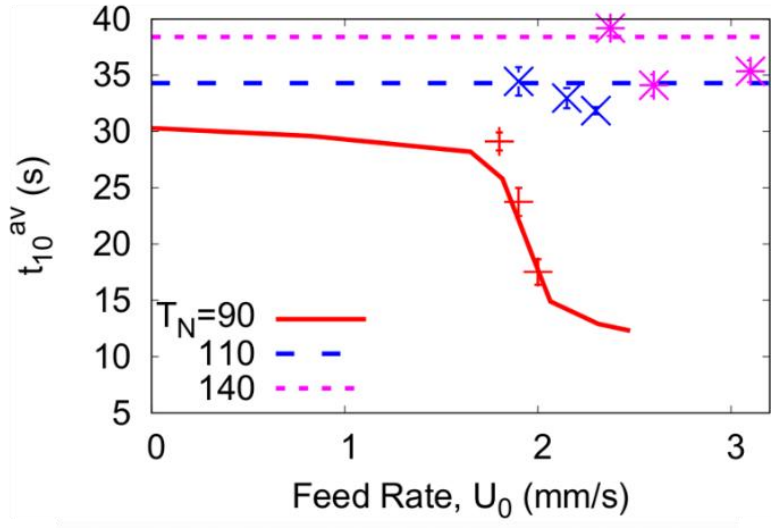

(d)

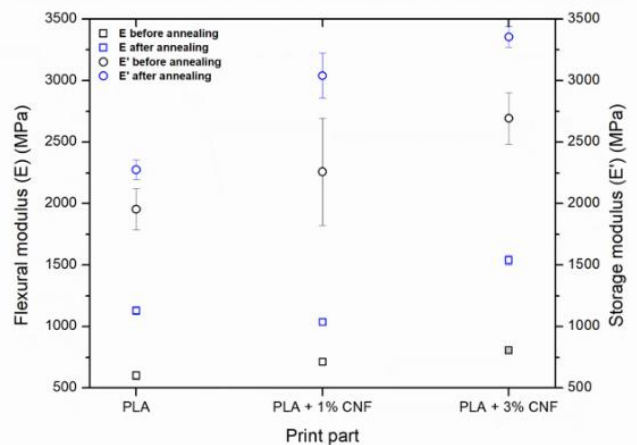

Fig. 6: (a) Effect of changes in percent crystallinity of printed part on the tensile strength of polyphenylene sulfide (data adapted from Ref. [87] with permission from Elsevier); (b) Flowinduced crystallization plot (image reprinted from Ref. [11] with permission from Elsevier); (c) Optical microscopy of annealed PLA printed cross-sections. Darker regions in the weld correspond to smaller sized spherulites due to flow-enhanced crystallization. The scale bar is 200 $\mu \mathrm{m}$. (image reprinted with permission from Ref. [79] Copyright 2019 American Chemical Society); (d) Improvement in tensile and flexural properties post-annealing for 3D printed PLA and PLA/cellulose nanofiber (CNF) composites (data adapted from Ref. [101] with permission from Elsevier). 
Table 1: Summary of the modeling approaches in material extrusion based additive manufacturing along with the polymer materials that were used to validate the models. The checkmarks indicate the fundamental models that were analyzed in the corresponding studies. The terms within parenthesis in the Materials column indicate the scale (road/part) of the simulation performed. It is worth mentioning that the term "road" has been used to denote both the extrudate exiting the nozzle and the material that is deposited on the printer bed.

\begin{tabular}{|c|c|c|c|c|c|c|}
\hline Study & $\begin{array}{l}\text { Flow } \\
\text { model }\end{array}$ & $\begin{array}{l}\text { Heat } \\
\text { transfer }\end{array}$ & $\begin{array}{c}\text { Viscoelasticity/ } \\
\text { Rheology }\end{array}$ & Crystallization & $\begin{array}{c}\text { Material } \\
\text { (Scale) }\end{array}$ & Reference \\
\hline $\begin{array}{c}\text { McIlroy \& } \\
\text { Graham } \\
2018 \\
\end{array}$ & $\checkmark$ & $\checkmark$ & $\checkmark$ & $\checkmark$ & PCL (road) & [11] \\
\hline $\begin{array}{l}\text { Serdeczny } \\
\text { et al. } 2018\end{array}$ & $\checkmark$ & & & & PLA (road) & [32] \\
\hline $\begin{array}{c}\text { Agassant } \\
\text { et al. } 2019\end{array}$ & $\checkmark$ & $\checkmark$ & $\checkmark$ & & ABS (road) & [33] \\
\hline $\begin{array}{c}\text { Gleadall } \\
\text { et al. } 2018\end{array}$ & $\checkmark$ & & & & PLA (road) & [34] \\
\hline $\begin{array}{l}\text { Costa et } \\
\text { al. } 2017\end{array}$ & & $\checkmark$ & & & $\begin{array}{l}\text { ABS (multi- } \\
\text { roads) }\end{array}$ & [36] \\
\hline $\begin{array}{c}\text { Bakrani } \\
\text { Balani et } \\
\text { al. } 2019 \\
\end{array}$ & $\checkmark$ & & $\checkmark$ & & PLA (road) & [38] \\
\hline $\begin{array}{c}\text { Hebda et } \\
\text { al. } 2019\end{array}$ & $\checkmark$ & & & & $\begin{array}{c}\text { PLA \& ABS } \\
\text { (road) }\end{array}$ & [30] \\
\hline $\begin{array}{l}\text { Comminal } \\
\text { et al. } 2018\end{array}$ & $\checkmark$ & & & & PLA (road) & [31] \\
\hline $\begin{array}{c}\text { Xia et al. } \\
2019\end{array}$ & $\checkmark$ & $\checkmark$ & $\checkmark$ & & PLA (road) & [39] \\
\hline $\begin{array}{c}\text { Gilmer et } \\
\text { al. } 2019\end{array}$ & & $\checkmark$ & & & PEI (road) & [40] \\
\hline $\begin{array}{c}\text { Xia et al. } \\
2019\end{array}$ & $\checkmark$ & $\checkmark$ & $\checkmark$ & & $\begin{array}{l}\text { PLA (multi- } \\
\text { roads) }\end{array}$ & [41] \\
\hline $\begin{array}{l}\text { Heller et } \\
\text { al. } 2016\end{array}$ & $\checkmark$ & & $\checkmark$ & & ABS (road) & [42] \\
\hline $\begin{array}{l}\text { Mackay et } \\
\text { al. } 2017\end{array}$ & $\checkmark$ & $\checkmark$ & & & $\begin{array}{c}\text { PLA \& ABS } \\
\text { (road) }\end{array}$ & [44] \\
\hline $\begin{array}{c}\text { Ravoori et } \\
\text { al. } 2019\end{array}$ & & $\checkmark$ & & & PLA (road) & [45] \\
\hline $\begin{array}{l}\text { Compton } \\
\text { et al. } 2017\end{array}$ & & $\checkmark$ & & & $\begin{array}{c}\text { CF/ABS } \\
\text { (part) }\end{array}$ & [51] \\
\hline $\begin{array}{c}\text { Osswald } \\
\text { et al. } 2018\end{array}$ & $\checkmark$ & $\checkmark$ & & & ABS (road) & [52] \\
\hline $\begin{array}{l}\text { Costa et } \\
\text { al. } 2015 \\
\end{array}$ & & $\checkmark$ & $\checkmark$ & & $\begin{array}{l}\text { ABS (multi- } \\
\text { roads) }\end{array}$ & [53] \\
\hline D'Amico & & & & & & \\
\hline
\end{tabular}




\begin{tabular}{|c|c|c|c|c|c|c|}
\hline $\begin{array}{c} \\
\text { Peterson } \\
2018\end{array}$ & & $\checkmark$ & & & $\begin{array}{l}\text { ABS (multi- } \\
\text { roads) }\end{array}$ & {$[55$} \\
\hline $\begin{array}{l}\text { Zhang et } \\
\text { al. } 2017\end{array}$ & & $\checkmark$ & & & $\begin{array}{l}\text { PLA (multi- } \\
\text { roads) }\end{array}$ & {$[56$} \\
\hline $\begin{array}{c}\text { Zhou et al. } \\
2017\end{array}$ & & $\checkmark$ & & & PLA (part) & {$[57$} \\
\hline $\begin{array}{c}\text { Zhou \& } \\
\text { Hsieh } \\
2017\end{array}$ & & $\checkmark$ & & & PLA (part) & {$[58$} \\
\hline $\begin{array}{c}\text { Zhang \& } \\
\text { Shapiro } \\
2018\end{array}$ & & $\checkmark$ & & & ABS (part) & {$[59$} \\
\hline $\begin{array}{c}\text { Luo et al. } \\
2020\end{array}$ & & $\checkmark$ & & & ABS (road) & {$[60$} \\
\hline $\begin{array}{c}\text { Coasey et } \\
\text { al. } 2020\end{array}$ & & $\checkmark$ & & & ABS (part) & {$[63$} \\
\hline $\begin{array}{c}\text { Edwards } \\
\text { \& Mackay } \\
2019\end{array}$ & & $\checkmark$ & & & $\begin{array}{c}\text { ABS \& PLA } \\
\text { (road) }\end{array}$ & {$[65$} \\
\hline $\begin{array}{l}\text { Ravoori et } \\
\text { al. } 2019\end{array}$ & & $\checkmark$ & & & $\begin{array}{l}\text { PLA (multi- } \\
\text { roads) }\end{array}$ & {$[66$} \\
\hline $\begin{array}{l}\text { Prajapati } \\
\text { et al. } 2018\end{array}$ & & $\checkmark$ & & & ABS (road) & {$[67]$} \\
\hline $\begin{array}{c}\text { Phan et al. } \\
2018\end{array}$ & $\checkmark$ & $\checkmark$ & $\checkmark$ & & PLA (road) & {$[68$} \\
\hline $\begin{array}{c}\text { Brenken } \\
\text { et al. } 2019\end{array}$ & & $\checkmark$ & $\checkmark$ & $\checkmark$ & $\begin{array}{c}\text { CF/PPS } \\
\text { (part) }\end{array}$ & {$[69$} \\
\hline $\begin{array}{c}\text { Phan et al. } \\
2020\end{array}$ & $\checkmark$ & $\checkmark$ & $\checkmark$ & & PLA (road) & {$[64$} \\
\hline $\begin{array}{c}\text { McIlroy \& } \\
\text { Olmsted } \\
2017\end{array}$ & $\checkmark$ & $\checkmark$ & $\checkmark$ & & $\begin{array}{l}\text { PC (multi- } \\
\text { roads) }\end{array}$ & {$[72$} \\
\hline $\begin{array}{c}\text { McIlroy et } \\
\text { al. } 2019\end{array}$ & $\checkmark$ & $\checkmark$ & $\checkmark$ & $\checkmark$ & $\begin{array}{l}\text { PLA (multi- } \\
\text { roads) }\end{array}$ & {$[79$} \\
\hline $\begin{array}{c}\text { McIlroy \& } \\
\text { Olmsted } \\
2017\end{array}$ & $\checkmark$ & & $\checkmark$ & & PC (road) & {$[80$} \\
\hline $\begin{array}{c}\text { Anderegg } \\
2020\end{array}$ & & $\checkmark$ & $\checkmark$ & $\checkmark$ & $\begin{array}{l}\text { PEI (multi- } \\
\text { roads) }\end{array}$ & {$[88$} \\
\hline $\begin{array}{c}\text { Duty et al. } \\
2017\end{array}$ & $\checkmark$ & & $\checkmark$ & & $\begin{array}{c}\text { CF/ABS } \\
\text { (multi-roads) }\end{array}$ & {$[94$} \\
\hline $\begin{array}{l}\text { Stupp } \\
2019\end{array}$ & $\checkmark$ & $\checkmark$ & $\checkmark$ & & - & {$[99$} \\
\hline
\end{tabular}

